BMJ Paediatrics Open

\title{
Experiences of pain in paediatric chronic fatigue syndrome/myalgic encephalomyelitis: a single-centre qualitative study
}

\author{
Teona Serafimova (D) , Caitlin Ascough (D) , Roxanne Morin Parslow, \\ Esther Crawley
}

To cite: Serafimova T, Ascough C, Parslow RM et al. Experiences of pain in paediatric chronic fatigue syndrome/myalgic encephalomyelitis: a singlecentre qualitative study. BMJ Paediatrics Open 2022;6:e001201. doi:10.1136/ bmjpo-2021-001201

- Additional supplemental material is published online only. To view, please visit the journal online (http://dx.doi.org/ 10.1136/bmjpo-2021-001201).

Received 24 June 2021 Accepted 8 September 2021

\section{Check for updates}

C) Author(s) (or their employer(s)) 2022. Re-use permitted under CC BY-NC. No commercial re-use. See rights and permissions. Published by BMJ.

Centre for Academic Child Health, University of Bristol, Bristol, UK

Correspondence to Dr Teona Serafimova; teona serafimova@nhs.net

\begin{abstract}
Background Moderate to severe pain affects up to two-thirds of children with chronic fatigue syndrome/ myalgic encephalomyelitis (CFS/ME) and is associated with worse fatigue and physical functioning. This research aims to gain a greater insight into pain experienced by these children.
\end{abstract}

Methods Thematic analysis of qualitative data from semistructured interviews with 13 children with CFS/ME (mean age $=15.3$ years, $67 \%$ female) was completed. Results Thematic analysis enabled construction of three themes: children's wide-ranging experiences of pain, negative impact of pain and lack of effective treatment for pain and nine subthemes. The first theme demonstrated highly varied pain experiences, ranging from 'like [being]... on fire', like 'being stabbed' to 'like... lead'. Children experienced pain in multiple sites and with wide-ranging frequency and severity. The second theme highlighted the profound negative impact of pain on multiple aspects of children's lives. Physical activity was severely impaired; some children 'couldn't leave bed' or 'couldn't... brush [their] own hair'. Abdominal pain meant some would 'go... days without eating'. Pain substantially impacted on mental health, leaving children feeling 'agitated', experiencing 'really bad panic attacks' or making them '[want to] breakdown'. Children felt they 'can't do the things that everyone else can do', had 'missed out' and are 'behind everyone'. Some avoided socialising as they 'don't want to stop everyone else'. The final theme demonstrates the absence of adequate treatment for pain, with participants reporting 'nothing has ever really got rid of it' and only 'slightly [takes] the edge off' and other experiencing side effects.

Conclusions Pain in paediatric CFS/ME is highly variable, common and often results in severe physical limitation and poor mental health. Effective treatments for pain represent an unmet need.

\section{BACKGROUND}

Chronic fatigue syndrome/myalgic encephalomyelitis (CFS/ME) is a common disorder affecting between approximately $0.1 \%$ and $0.89 \%$ of children and adolescents ${ }^{12}$ which can be disabling. ${ }^{2-4}$ It primarily involves severe fatigue but moderate to severe pain is

\section{What is known about the subject?}

Moderate to severe pain affects nearly $60 \%$ of children with chronic fatigue syndrome/myalgic encephalomyelitis (CFS/ME). No specific treatments exist for pain in paediatric CFS/ME

\section{What this study adds?}

Pain is variable, common and results in physical limitation and poor mental health for children with CFS/ME. Effective treatments for pain represent an unmet need.

common affecting over $60 \%$ of children with $\mathrm{CFS} / \mathrm{ME},{ }^{5}$ compared with between $3.6 \%$ and $16.6 \%$ of healthy children. ${ }^{6}$ The pain experienced by children with CFS/ME may have similar underlying aetiopathological mechanisms to paediatric chronic pain syndrome. ${ }^{78}$ Chronic pain in paediatric CFS/ME is associated with worse fatigue and poor physical functioning. ${ }^{5}$

Pain in paediatric CFS/ME is poorly understood and there are no treatments specifically targeting pain in this population. Only five treatment studies included pain as an outcome measure. ${ }^{10}$ In these studies, treatments included (CBT (cognitive behaviour therapy), a 'self-confrontation method', the Lightning Process and low-dose clonidine). No intervention resulted in a significant reduction in pain although two studies suggested that pain may improve in those who are 'recovered' compared with 'non-recovered'. Current NICE (National Institue for Health and Care Excellence) guidelines, for patients with CFS/ME from 5 years old to adulthood, suggest low-dose amitriptyline, 'relaxation techniques' and consideration of referral to chronic pain services, if appropriate. ${ }^{11} \mathrm{No}$ 
specific guidelines exist for children. Although amitriptyline is used for pain in paediatric CFS/ME, there is no trial evidence to support its efficacy. In paediatric chronic pain more generally, multimodal interdisciplinary interventions have yielded positive results thus far, ${ }^{12}$ although within small studies.

Understanding children's experiences of pain is important to develop targeted interventions as in other conditions. ${ }^{13-15}$ This paper aims to describe the experience of pain, its impact and treatments, in children with CFS/ME using a person-centred perspective.

\section{METHODS}

\section{Study design}

Qualitative interviews were conducted as part of two studies (a feasibility study and a full study) investigating pain using quantitative sensory testing (QST). Data collection was conducted between January 2019 and January 2020. All children who attended for QST were invited to participate in a single qualitative interview. Recruitment was terminated prematurely due to the COVID-19 pandemic; it is difficult to assess whether data saturation was reached.

\section{Participants}

Children were recruited through purposive sampling from a specialist paediatric CFS/ME service and were eligible if they were: aged between 11 and 17 years; diagnosed with CFS $/ \mathrm{ME}^{11}$ and able to attend a single study visit. Exclusion criteria included: children unable to attend an outpatient appointment, children with neurological comorbidity and children who were unable to undertake QST. Children did not have to have pain to participate.

Health professionals informed children and their families about the study, provided patient information and obtained consent/assent to contact. The researcher obtained consent. Participants received a $£ 15$ gift voucher following completion of the study.

\section{Qualitative data collection}

A semistructured topic guide (online supplemental appendix 1) was developed to guide qualitative interviews, based on previous work exploring children's experiences of $\mathrm{CFS} / \mathrm{ME}^{3}{ }^{3}$ The topic guides explored children's experiences of CFS/ME, their experiences of pain and the impact of pain on their lives. Children were also asked about their experiences of QST. Qualitative interviews were conducted via phone, Skype or in person, according to participant preference. CA conducted four interviews; TS undertook nine interviews, with training from RMP. Interviewers had no interactions with participants outside of the study. Interviews were conducted on a one-to-one basis, although parents were present in some cases. Interviews were recorded with consent, on an encrypted digital audio recorder, transcribed verbatim and anonymised. No field notes were made. Transcripts were not returned to participants.

\section{Qualitative data analysis}

Thematic analysis was conducted using NVIVO 12 Pro. ${ }^{16}$ Transcripts were read several times to facilitate familiarity and were checked for accuracy. Transcripts for subgroups (males vs females, children $\leq 15$ years vs those $>15$ years) were coded separately. The codes were compared between the subgroups searching for similarities and differences in the data and the coding framework was expanded as coding progressed to reflect the different experiences. This helped identify themes which do not appear in all parts of the data. ${ }^{17}$ Some of the qualitative data were quantified (eg, the number of participants taking analgesics) to aid data interpretation.

We were particularly interested in descriptions of pain (location and frequency), its impact and the different experiences of treatment between children. Therefore, data analysis initially used deductive codes derived from topic guides and structured on these broad 'sensitising concepts'. ${ }^{18}$ Transcripts were read and re-read to develop inductive codes and expand on the deductive codes using participants' own language. Codes were reviewed and combined or separated, as further interviews were conducted to provide more detail on the dimensions of the themes, expanding the coding framework. Six transcripts were double coded (RMP) and compared with improve the trustworthiness of the analysis and aid the interpretation of the data. Participant feedback has not yet been sought.

\section{Patient and public involvement}

All study documentation was adapted from previous studies in paediatric CFS/ME that had significant input from the young person's advisory group (PAG). They have been designed based on the guidance published by the NIHR (National Institute for Health Research) Medicines for Children Research Network Young Person's Advisory Group. The study's research aims and design were discussed with the young person's CFS/ME PAG prior to seeking ethical approval and commencing the study. This group was made up of young people with a diagnosis of CFS/ME and included a male and female patient at different stages of recovery. The research team will continue to consult with them with regard to dissemination of the study.

\section{RESULTS}

Overall, 15 children had QST, of which 13 were interviewed (two lost to follow-up). Most $(9 / 13,69 \%)$ were female, with a mean age of 15 years (range $=11-17$ years). Interviews were conducted via Skype ( $\mathrm{n}=6,46.2 \%)$, phone $(\mathrm{n}=6,46.2 \%)$ and in person at the University of Bristol $(\mathrm{n}=1,7.7 \%)$. Four interviews $(31 \%)$ were conducted with one or both parents present. Interviews lasted between 10 and 25 min. 
Table 1 Themes and subthemes

\begin{tabular}{ll}
\hline Main theme & Subthemes \\
\hline $\begin{array}{l}\text { Children's wide- } \\
\text { ranging experiences } \\
\text { of pain }\end{array}$ & $\begin{array}{l}\text { A spectrum of pain: ('dull' to 'being } \\
\text { stabsed') } \\
\text { Distribution of pain: from 'everywhere' } \\
\text { to specific body sites } \\
\text { Random to specific triggers for pain }\end{array}$ \\
$\begin{array}{l}\text { Negative impact of } \\
\text { pain }\end{array}$ & $\begin{array}{l}\text { Limited and altered participation in } \\
\text { education and leisure } \\
\text { Limiting basic daily activities } \\
\text { Negative impact of pain on mental } \\
\text { health }\end{array}$ \\
& $\begin{array}{l}\text { Pushing through despite the pain } \\
\text { A range of treatments (prescribed to } \\
\text { home treatments) } \\
\text { Limited to no impact on pain } \\
\text { Negative side effects }\end{array}$ \\
\hline
\end{tabular}

Overall, 12 of the 13 children interviewed experienced pain as part of their CFS. The results describe three themes: (A) children's wide-ranging experiences of pain, (B) negative impact of pain and (C) lack of effective treatments for pain (table 1).

\section{Theme A: Children's wide-ranging experiences of pain}

A spectrum of pain: ('dull' to 'being stabbed')

Children described a range of distinct pain experiences, varying in character, location, frequency, onset, triggers and intensity of their pain (table 2 ).

Some children had very severe pain (see quotes 1a, 1b, 1d), while others experienced more subtle pain (1c, 1e). Of note, older children were able to use more complex language to describe their pain experiences (1a-1d). Some younger children found it hard to express what type of pain they experienced stating 'it's hard to describe' (P12).

\section{Distribution of pain: from 'everywhere' to specific body sites}

Children experienced pain at multiple sites. A wide variety of locations were described, most commonly: the back, legs and neck ( $2 \mathrm{a}-2 \mathrm{~g})$. Others were unable to pinpoint distinct painful areas and experienced pain throughout their bodies $(2 \mathrm{~g}, 2 \mathrm{~h})$. Two participants experienced heightened sensitivity in their skin and hair $(2 \mathrm{j}, 2 \mathrm{k})$, particularly triggered by touch.

\section{Random to specific triggers for pain}

While some children were unable to identify a clear trigger for their pain $(3 \mathrm{a}, 3 \mathrm{~b})$, several identified physical activity, 'walking... and any kind of sport' (3c) and/ or 'tiredness' (3d-3f) triggering or worsening pain. Two participants found that pain was linked to temperature, experiencing worse pain in colder climates $(3 \mathrm{~g}, 3 \mathrm{~h})$. Others found pain was triggered by sensory stimuli. Specifically, two children who experienced headaches frequently found that auditory and visual stimuli worsened pain $(3 \mathrm{i}, 3 \mathrm{j})$.
Theme B: Negative impact of pain

Limited and altered participation in education and leisure

Pain limited children from participating in a range of activities, including sports, dog walks, gardening, spending time with friends and attending school (table 3)

One child was unable to attend school some days due to pain (4a), while others found pain interfered with other aspects of education (4b-4e) including the ability to concentrate (4b) and write (4c). Another participant found her school uniform exacerbated the pain she experienced in her skin (4e).

Children's participation in physical activity was severely limited due to pain. Some children could not take part in sport $(4 \mathrm{~g}, 4 \mathrm{~h})$, while another had to be more careful to avoid exacerbating the pain (4f). Three children could not walk at the same pace as their peers due to pain $(4 \mathrm{i}-4 \mathrm{k})$ which impacted on their social lives. Sensitivity to audio-visual stimuli meant one teenager found going to the cinema too painful and sometimes found sunshine too bright to tolerate (4l).

While most children described some impact of pain on their daily activities, older children expressed more of an impact on social activities-'my friends used to go down town and spend the day there...I couldn't barely last a few hours' (4k) as well as their relationships with friends-'I don't want to stop everyone else just because I'm in pain' $(4 \mathrm{i})$.

\section{Limiting basic daily activities}

Daily activities were limited by pain for several children. Two children found mobilising around their homes challenging due to pain $(5 \mathrm{a}, 5 \mathrm{~b}, 5 \mathrm{f})$. One described pain during any movement (5c). Two young people found that abdominal pain prevented them from eating $(5 \mathrm{c}$, $5 d$ ). One teenager experienced pain that prevented her from carrying out self-care activities (5e), requiring help from her family. She also found it had a noticeable impact on her sleep (5f).

\section{Negative impact of pain on mental health}

The majority of children interviewed described a negative impact of pain on their mental health.

Some children found pain was intricately linked to feelings of anxiety. One young person explained that his pain was related to his levels of stress (6a). Another described anxiety related to increasing her activity levels and whether this would worsen pain (6b). For one participant, pain became so severe that she became bed bound, resulting in profound worsening of her mental health and panic attacks (6c). One teenager found his pain was so severe that it made him feel like breaking down (6d), while another felt 'miserable' (6e). Two young people found pain made them frustrated (6f, $6 \mathrm{~g})$.

Several participants described the impact of activity limitation on their mental health. Pain meant that they 
Table 2 Participant quotes relating to theme A: Children's wide-ranging experiences of pain

Quote

Code

A spectrum of pain

It feels like l'm being stabbed when there's like, a sharp spike. It feels like l've been stabbed and sometimes it just goes like...where 1a it's stabbing and stabbing. (P7)

It feels like you're on fire. (P4)

$1 b$

It can go anything from like... a dull background to I dunno, like, if my arms hurt and I try to lift them you're just like 'ooh' you know it's $1 \mathrm{C}$ like a jab. (P11)

It feels really like tight... like when you accidently prick yourself like with a pin or something.... it feels like a load of pins in muscles $1 \mathrm{~d}$ hurting it quite a bit. (P1)

The worst pain is in my back cos it's like a pain that actually like hurts, the rest of it's kind of, just more uncomfortable, um and like, $1 \mathrm{e}$ subtle in a way, I guess like, the pain my back is like, I wanna say pounding but not, pounding's not the right word cos it doesn't do that, but it's like, stronger. (P9)

Distribution of pain: from everywhere' to specific body sites

It's more noticeable in, in like my back, particularly like my upper back and over my shoulders. (P11)

In my neck my arms and my legs, and I get pain in my hands and my feet as well. I get pain everywhere, really. (P9)

$2 b$

A lot in my neck, on the right-hand side of my neck as well, at the bottom, and at the top...but then also lower down the spine nearer $2 \mathrm{c}$ to my hips. (P5)

Walking upstairs, like, all my bones and stuff all start to hurt. (P1)

I started getting joint pain then. But it's kind of like, every, every joint really. (P4)

$2 \mathrm{~d}$

I get a lot of headaches and migraines and I also just get general like joint pain. I used to have a lot of back problems, where it would $2 f$ like kind of like be really painful to move my back at all. (P2)

Walking up like stairs and that like, l'll always be in pain like in my legs...and just like my joints in general. (P1)

e

Pretty much everywhere. (P11)

Headaches, throat aches, stomach aches where I can't eat for weeks um, I basically just get pain all over my body. (P12)

My skin, it'll all really hurt and be sensitive so like, anything touching it will hurt. (P1)

(She finds) some things are very sensitive to touch and to brush some of [her] hair was very painful, because I think there's certain things, when her skin just becomes more, um, more sensitive. (Father, P3)

I get [abdominal pain] if I'm nervous but sometimes it's like not if I'm nervous because I'm run down. But it's still like that similar pain 2 I to when you're nervous. (P1)

Random to specific triggers for pain

(Don't)know what brings it on, it just happens. (P9)

It's very random... And then one day I could go like barely even feeling it and like the next day it could be bad. (P8) 3a

Is normally there, but it's like, sometimes, it'll just randomly show up if I do walking... and well, really any kind of sport as well. (P6)

My legs hurt but that's cos...l've come back from school so l'm tired. (P11)

Tiredness definitely makes it a lot worse. (P2)

It's more, prominent on days where I have to do like a lot in a day. (P11)

In the cold it gets really bad. (P4)

It just tends to hurt a lot more when l'm cold. (P6)

$2 e$

$2 f$

$2 \mathrm{~g}$

$2 \mathrm{~h}$

$2 \mathrm{i}$

$2 \mathrm{j}$

$2 \mathrm{k}$

I have to shut my ears cos it's too loud or, like the bright lights I find, like too much. (P4)

If there's like, loud noises...or like big, like flashy lights, then that just makes it quite a lot worse. (P2)

$3 c$

$3 d$

$3 d$

$3 e$

$3 f$

$3 g$

$3 \mathrm{~h}$

$3 i$

$3 \mathrm{j}$

felt left behind compared with their peers $(6 \mathrm{~h}-6 \mathrm{k})$ and subsequently felt different or isolated.

Pushing through despite the pain

Some children were able to continue with activities despite pain. One teenager described it as something they have 'just grown up with' and so persevered with most of his activities (7a). Others endured pain to take part in activities $(7 \mathrm{c}, 7 \mathrm{~d})$. Participants showed resolve and determination despite pain $(7 \mathrm{c}-7 \mathrm{f})$.

Several children did not discuss their pain with their friends, family or professionals. One participant had never discussed his/her pain with anyone prior to the interview for this study $(7 \mathrm{c})$.
Theme C: Lack of effective treatment for pain

None of the children described complete resolution of pain with any treatment (table 4 ).

A range of treatments (prescribed to home treatments)

Nine of the children interviewed had used simple analgesics for pain. Five took analgesic medications daily or on most days. Medications named by participants included paracetamol, ibuprofen and amitriptyline. Children trialled a range of home treatments for pain, including massage, baths, vitamin supplementation, herbal teas, electric blankets and heat packs $(8 \mathrm{a}-8 \mathrm{i})$.

Three children experienced gastrointestinal symptoms as part of their chronic fatigue, but only one trialled 
Table 3 Participant quotes relating to theme B: Negative impact of pain

Quote

Code

Limited and altered participation in education and leisure

Sometimes I can't go out because it hurts so bad, so I have to cancel plans or I can't go to school cos it hurts too bad. (P7) $4 a$

It can be difficult to concentrate sometimes, especially if you have like a headache. (P11)

$4 b$

It affected my wrists obviously straight away, cos I was tryna write, so I couldn't really write much. In my exams, I had to type 4c everything up because I couldn't use them. (P4)

Right now, my legs hurt but that's cos I've been, I dunno, I've come back from school so I'm tired. (P11)

It was like my school trousers....those brushing on my legs like really hurt it. (P1)

$4 d$

$4 \mathrm{e}$

I'll just do something and it just really hurts so I tend to be a lot more careful when I do like, sports, like hockey and also karate, so, I just tend to take it a lot easier on those things. (P6)

Had to stop doing PE because that made [the pain] really bad. (P7)

Exercising in general is just something that l'd theoretically like to do but it's kind of difficult. (P2)

If I'm trying to walk with like some friends or something, it it's very painful. I don't want to stop everyone else just because I'm $4 \mathrm{I}$ in pain. So usually, I just walk alone and I can have my own break. (P8)

I can't walk very far without being in a lot of pain, which affects me quite a lot because a lot of my friends, like, walk fast and $4 \mathrm{j}$ far. (P9)

My friends used to go down town and spend the day there and do shopping and now like I couldn't, I couldn't barely last a few hours, a couple of hours or just come home and everything's aching. (P4)

Going to the cinema and stuff, a lot of times I have to shut my ears cos it's too loud or, like the bright lights I find, like too much. And even going out sometimes, out of my, like my front door, with the sun, it kind of just, like really hurts my eyes. (P4)

Limiting basic daily activities

Stops me from walking...just stops me from anything simple. (P12)

Going up stairs is a big problem. (P2)

(The pain) only stops if I just stop moving... It sort of just kind of makes you think what's the point of just going through it...I could withstand it but I don't see the point of withstanding it. (P8)

(The stomach pain) feels like it's like throbbing. Kind of, and like just like, tensing up really hard, um, but yeah, it like stops me $5 \mathrm{~d}$ from like eating and stuff. (P1)

Stomach aches where [they] can't eat for weeks. (P12) $5 e$

I couldn't even like, brush my own hair or anything. Like my parents had to do it all for me and like, help me like shower, like, do like everything, like, normal people should be able to do....even like, just like, walking up like stairs and that like, l'll always be in pain like in my legs. (P1)

(Pain) can like affect your sleeping as well, so, like for me, I find it really hard to sleep. (P1)

Negative impact of pain on mental health

I mean the only time [the pain] sort of stops is when I'm completely relaxed. (P8)

$6 a$

As soon as I kinda start moving, it will just get worse again and then I get worried, when I get home, what the aftereffects is $6 \mathrm{~b}$ gonna be like. (P4)

I had to go months without like, seeing my friends and just being like bed bound, so like, I used to have really like, on my own $6 \mathrm{c}$ and like alone and, that's my - my anxiety got even like worse then and like, because I was only around my mum, that's all, that's the only person I wanted to be with then, like doing anything without her l'd have like really bad panic attacks. (P1)

You know at my worst with chronic fatigue, it's when I'm at my complete, y'know, lowest with my mood...sometimes with the $6 \mathrm{~d}$ pain it's like, sometimes it can feel a bit like throbbing, um, and that can just be really like, you just wanna cry....you wanna breakdown about it but it's like you know, you're just holding it together. (P11)

I do get quite miserable sometimes from it. (P10)

I think it just brings your general mood down cos it's just like, y'know, just adding to the list of things to be annoyed about. (P11)

When I'm uncomfortable it makes me feel really agitated. (P9)

No one's gonna be happy when they can't move from bed. (P1)

It makes me upset because I can't do things that everyone else can do. (P7)

You see so many things happening and obviously when you go on your phone, you see everyone moving on and like, doing all $6 \mathrm{j}$ these life, life goals that they wanna do. And I'm just... yeah, I'm just behind everyone so... it does get to me a lot. (P4)

I wanna...not be in pain all the time but yeah I do think I have missed out on a lot that other people my age are doing. (P4) $6 \mathrm{k}$

Pushing through despite the pain

I've just gotten kind of used to it now, so I don't really, I don't even notice it. (P11)

$7 a$

Continued 


\begin{tabular}{|c|c|}
\hline Quote & Code \\
\hline Most of the time it's just like an irritant and I'm just like I'm always in a bad mood. (P11) & $7 \mathrm{~b}$ \\
\hline I don't, I don't tell anybody if I'm in pain, I just keep going. (P5) & $7 c$ \\
\hline I went to a festival... I was in pain, but I was like, I don't want to miss out on it. (P1) & $7 d$ \\
\hline $\begin{array}{l}\text { I kind of just tell myself to get on with it and [exasperated laugh] keep pushing through it, which probably isn't always the best } \\
\text { thing to do. (P5) }\end{array}$ & $7 e$ \\
\hline $\begin{array}{l}\text { I hate using chronic fatigue as an excuse for anything y'know, I don't wanna let something define me, control me, and I feel } \\
\text { like if I just get along with it, you know there are worse things going on in the world, like there are people staving I can live. } \\
\text { (P11) }\end{array}$ & $7 f$ \\
\hline
\end{tabular}

dietary modification to improve abdominal pain. One wore 'acupuncture bands' which he found effective for nausea $(8 c)$. He was also taking 'sulphidine and magnesium tablets' for pain (8i), in addition to conventional analgesic medication.

Children had not received any other interventions specifically targeting pain other than those mentioned.

Limited to no impact on pain

Response to analgesic medications was variable. Analgesia ranged from helpful $(9 a)$, partially effective $(9 b, 9 c)$ to helpful for some pain but not others (9d). Others felt that analgesia was not helpful at all (9e). As previously described, many children sought to avoid pain triggers in the absence of effective treatments for pain.

\section{Negative side effects}

Medication to manage pain resulted in negative side effects. One child described severe mood side effects secondary to amitriptyline (10a). Another explained that her doctor was concerned regarding possible side effects from frequent analgesic use (10b). Two teenagers found that non-pharmacological interventions for $\mathrm{CFS} / \mathrm{ME}$, such as physiotherapy (10c) and osteopathy (10d), worsened pain.

\section{Table 4 Participant quotes relating to theme C: Lack of effective treatment for pain}

Quote Code

A range of treatments (prescribed to home treatments)

I've had to buy like, an electric blanket for my room...so that if I wake up in the night, hopefully, I won't be in as much pain as I $8 a$ was before. (P4)

\begin{tabular}{|c|c|}
\hline Sometimes heat, like heat packs or stuff like that. They often make it better. (P5) & $8 \mathrm{~b}$ \\
\hline I've got bands for my wrists, the acupuncture bands...they seem to work... when I feel sick. (P10) & $8 \mathrm{c}$ \\
\hline $\begin{array}{l}\text { (My mother) will get me like, like, lavender bags, to put around my bed, cos that's supposed to like, relax your muscles...you'll } \\
\text { just fall asleep so you're like, oh did it work, did it not. (P1) }\end{array}$ & $8 d$ \\
\hline I have baths and I have like Epsom salts in them... and that helps like relax the muscles. (P1) & $8 e$ \\
\hline Massages help... like it feels like pressure, yeah, I guess pressure helps a little bit sometimes. (P9) & $8 f$ \\
\hline $\begin{array}{l}\text { I saw an osteopath for a little bit, umm, but, I mean, it didn't really do much, it did to begin with, like it felt nice and was more } \\
\text { comfortable, but it just got worse and can't do much for me anymore. (P9) }\end{array}$ & $8 g$ \\
\hline
\end{tabular}

\section{They put me on like, lactose intolerant diets cos I, I got, I get really bad tummy pains with(CFS/ME). (P1) $8 \mathrm{~h}$}

It's sulphidine and magnesium tablets I get. Not sure if they're counter or not. (P10)

Painkillers) might like, knock the pain down a bit but it's not like, it's not a permanent, like, relief of the pain. (P4)

The migraines don't really do much with painkillers but headaches and joint pains, generally works quite well. I don't think anything works with my knee, yet. (P2)

I don't feel like it's the kind of pain... that can be solved by like paracetamol or something. (P11)

$9 c$

Negative side effects

The effects haven't been good so l'm coming off of it now.... I've been sad quite a lot, and we think it's because of it, so we're gonna try and get off of it cos l've just been crying a lot... it's just being sad, but for no reason. (P7) 
DISCUSSION

Experiences of pain in paediatric CFS were highly individual and diverse. Children experienced a wide range of symptom severity and symptom frequency. For some, pain had clear triggers, while others found this to be unpredictable. Pain has a profound impact on children, affecting exercise, education, mental health and social activities. Children found treatments for pain to be largely ineffective, with some suffering side effects.

\section{Strengths and limitations}

The sample included children across a comprehensive age range. The majority of participants were female consistent with other studies. ${ }^{219}$ Data analysis was systematic with double coding from independent researchers.

Although we did not set out specifically to recruit children with pain, children with pain may have been more inclined to participate. Clinicians were encouraged to discuss the study with all eligible patients; however, they may have been more likely to discuss it with children with pain or who mentioned pain during their appointment. The interviewers were both doctors, which may have biased lines of questioning and analysis. Further, given this sample was recruited from a specialist CFS/ ME service, there may be an over-representation of severe cases which may be disproportionately affected by pain.

Future research would benefit from recruiting a larger sample size. A larger sample size should also aim to recruit more children managed in primary care, male children and children from minority backgrounds, to ensure their experiences are represented. Our small sample size, due to recruitment being stopped prematurely, prevented subgroup analysis. Larger sample sizes would allow researchers to evaluate specific pain experiences, such as in primary versus secondary school aged children. Although we noticed some differences between older and younger children, our sample size was too small to draw definitive conclusions.

While a minority of children were interviewed together with their parents, children' parents may have been present during the interview, without the interviewer's knowledge. Parental presence may have modified children's responses, particularly surrounding sensitive or difficult topics. ${ }^{20}{ }^{21}$ Children's use of language may have also changed, due to the presence of their parent(s) and/or the interviewer. Examining parental perspectives of their child's pain could provide a more complete understanding. Future studies could ensure parents and children and interviewed separately, where feasible and acceptable.

Pain is a common, highly variable symptom associated with paediatric CFS/ME, which has a substantial impact on children's well-being. Healthcare professionals caring for children with CFS/ME should explore pain with patients, as children may not discuss this without prompting. Pain, where present, is likely to contribute significantly to fatigue, activity limitation and mental ill health and vice versa. Understanding how these symptoms are inter-related and the impact on children will be valuable in understanding the specific pain experiences of children with CFS/ME compared with those with other chronic pain conditions.

Gaining further temporal data exploring fluctuations in pain, associations between pain and other CFS/ME symptoms and an improved understanding of the underlying pathophysiology of chronic pain in paediatric CFS/ME may result in optimised treatments. Interdisciplinary multimodal approaches with a specific focus on pain may be of benefit in this population.

Acknowledgements The authors would like to thank all the participants who took part and their families. The authors are grateful to the clinicians and supporting staff at the paediatric chronic fatigue syndrome/myalgic encephalomyelitis service who facilitated the identification and recruitment of participants.

Contributors EC, CA and TS designed the study. TS and CA collected the data. TS and RMP analysed the data. All authors contributed to the interpretation of results and drafting of the paper and read and approved the final version of the manuscript. EC is responsible for the overall content as the guarantor.

Funding The authors have not declared a specific grant for this research from any funding agency in the public, commercial or not-for-profit sectors.

\section{Competing interests None declared.}

Patient consent for publication Not applicable.

Ethics approval Ethics approval was obtained from NHS (National Health Service) Research Ethics Committee (19/SW/0233), University of Bristol, and the relevant research and development department.

Provenance and peer review Not commissioned; externally peer reviewed.

Data availability statement All data relevant to the study are included in the article or uploaded as supplementary information. All relevant data have been presented in the manuscript.

Supplemental material This content has been supplied by the author(s). It has not been vetted by BMJ Publishing Group Limited (BMJ) and may not have been peer-reviewed. Any opinions or recommendations discussed are solely those of the author(s) and are not endorsed by BMJ. BMJ disclaims all liability and responsibility arising from any reliance placed on the content. Where the content includes any translated material, BMJ does not warrant the accuracy and reliability of the translations (including but not limited to local regulations, clinical guidelines, terminology, drug names and drug dosages), and is not responsible for any error and/or omissions arising from translation and adaptation or otherwise.

Open access This is an open access article distributed in accordance with the Creative Commons Attribution Non Commercial (CC BY-NC 4.0) license, which permits others to distribute, remix, adapt, build upon this work non-commercially, and license their derivative works on different terms, provided the original work is properly cited, appropriate credit is given, any changes made indicated, and the use is non-commercial. See: http://creativecommons.org/licenses/by-nc/4.0/.

\section{ORCID iDs}

Teona Serafimova http://orcid.org/0000-0001-7445-9728

Caitlin Ascough http://orcid.org/0000-0002-2266-3433

Esther Crawley http://orcid.org/0000-0002-2521-0747

\section{REFERENCES}

1 Lim E-J, Ahn Y-C, Jang E-S, et al. Systematic review and metaanalysis of the prevalence of chronic fatigue syndrome/myalgic encephalomyelitis (CFS/ME). $J$ Transl Med 2020;18.

2 Nijhof SL, Maijer K, Bleijenberg G, et al. Adolescent chronic fatigue syndrome: prevalence, incidence, and morbidity. Pediatrics 2011;127:e1169-75.

3 Parslow RM, Anderson N, Byrne D, et al. Adolescent's descriptions of fatigue, fluctuation and payback in chronic fatigue syndrome/ myalgic encephalopathy (CFS/ME): interviews with adolescents and parents. BMJ Paediatr Open 2018;2:e000281. 
4 Garralda ME, Rangel L. Impairment and coping in children and adolescents with chronic fatigue syndrome: a comparative study with other paediatric disorders. J Child Psychol Psychiatry 2004;45:543-52.

5 Collin SM, Nuevo R, van de Putte EM, Crawley E, et al. Chronic fatigue syndrome (CFS) or myalgic encephalomyelitis (Me) is different in children compared to in adults: a study of UK and Dutch clinical cohorts. BMJ Open 2015;5:e008830.

6 Perquin CW, Hazebroek-Kampschreur AAJM, Hunfeld JAM, et al. Pain in children and adolescents: a common experience. Pain 2000;87:51-8.

7 Meeus M, Nijs J. Central sensitization: a biopsychosocial explanation for chronic widespread pain in patients with fibromyalgia and chronic fatigue syndrome. Clin Rheumatol 2007;26:465-73.

8 Norris T, Deere K, Tobias JH, et al. Chronic fatigue syndrome and chronic widespread pain in adolescence: population birth cohort study. J Pain 2017;18:285-94.

9 May M, Emond A, Crawley E. Phenotypes of chronic fatigue syndrome in children and young people. Arch Dis Child 2010;95:245-9.

10 Ascough C, King H, Serafimova T, et al. Interventions to treat pain in paediatric CFS/ME: a systematic review. BMJ Paediatr Open 2020;4:e000617.

11 NICE. Chronic fatigue syndrome/myalgic encephalomyelitis (or encephalopathy): diagnosis and management. Natl Inst Heal Care Excell 2007 https://www.nice.org.uk/guidance/cg53
12 Liossi C, Johnstone L, Lilley S, et al. Effectiveness of interdisciplinary interventions in paediatric chronic pain management: a systematic review and subset meta-analysis. Br J Anaesth 2019;123:e359-71.

13 Rabbitts JA, Aaron RV, Fisher E, et al. Long-Term pain and recovery after major pediatric surgery: a qualitative study with teens, parents, and perioperative care providers. J Pain 2017;18:778-86.

14 Sng QW, Taylor B, Liam JL, et al. Postoperative pain management experiences among school-aged children: a qualitative study. J Clin Nurs 2013;22:958-68.

15 Idvall E, Holm C, Runeson I. Pain experiences and nonpharmacological strategies for pain management after tonsillectomy: a qualitative interview study of children and parents. J Child Health Care 2005;9:196-207.

16 QSR International Pty Ltd. NVivo qualitative data analysis software. 12, 2019.

17 Ritchie J, Lewis J. Qualitative research practice: a guide for social science students and researchers. 2 edn. SAGE, 2013.

18 Bowen GA. Grounded theory and sensitizing concepts. Int J Qual Methods 2006.

19 Knight S, Elders S, Rodda J, et al. Epidemiology of paediatric chronic fatigue syndrome in Australia. Arch Dis Child 2019;104:733-8.

20 Mauthner M. Methodological aspects of collecting data from children: lessons from three research projects. Child Soc 1997.

21 Hafetz J, Miller VA. Child and parent perceptions of monitoring in chronic illness management: a qualitative study. Child Care Health Dev 2010;36:655-62. 